\title{
Commentary: Can we finally move the needle in organ donation?
}

\author{
Jonathan W. Haft, MD
}

From the Department of Cardiac Surgery, University of Michigan, Ann Arbor, Mich.

Disclosures: Author has nothing to disclose with regard to commercial support.

Received for publication July 5, 2019; accepted for publication July 5, 2019; available ahead of print Aug 14, 2019.

Address for reprints: Jonathan W. Haft, MD, University of Michigan, Cardiac Surgery, 48109 Ann Arbor, MI (E-mail: haft@umich.edu).

J Thorac Cardiovasc Surg 2020;159:514

$0022-5223 / \$ 36.00$

Copyright (c) 2019 by The American Association for Thoracic Surgery

https://doi.org/10.1016/j.jtcvs.2019.07.007

This expert opinion by Jawitz and Milano ${ }^{1}$ in this issue of the Journal discusses the rapidly evolving topic of transplantation of hearts obtained through donation after cardiac death (DCD). Jawitz and Milano ${ }^{1}$ reviewed the experiences by 2 groups leading the efforts in revitalizing interest in cardiac DCD (United Kingdom and Australia). The outcomes have been promising, with the exception of increased shortterm use of extracorporeal membrane oxygenation. Jawitz and Milano ${ }^{1}$ suggest from their analysis and other estimates that widespread adoption of DCD cardiac donation could potentially increase the donor pool by as much as $30 \%$, an enviable statistic given the growing imbalance between eligible recipients and transplants performed.

As Jawitz and Milano ${ }^{1}$ point out, however, there is much work to be done. There remain potential ethical challenges: (1) the dilemma of cardiac reanimation when the very definition of DCD is cardiac standstill, (2) invasive diagnostic testing in the donor (approximately $50 \%$ of brain dead donors currently undergo cardiac catheterization), (3) antemortem interventions to facilitate the donation process (heparinization, vascular access), (4) standardized definitions of cardiac death (cessation of all electrical activity versus lack of detectible cardiac impulse), (5) universally accepted standoff duration, and (6) potential impact on currently accepted processes used for DCD abdominal organ transplantation. In addition, the encouraging results from these leading centers may be biased by the highly selective donor criteria and short allowable warm ischemic time. Furthermore, the experiences of both centers rely heavily on their use of the costly TransMedics Organ Care System (OCS; TransMedics, Inc, Andover, Mass), which is currently unapproved by the Food and Drug Administration in the United States. Although the OCS provides biochemical data (lactate production and consumption), there is no functional assessment of the donor heart. For widespread adoption of DCD heart transplantation,

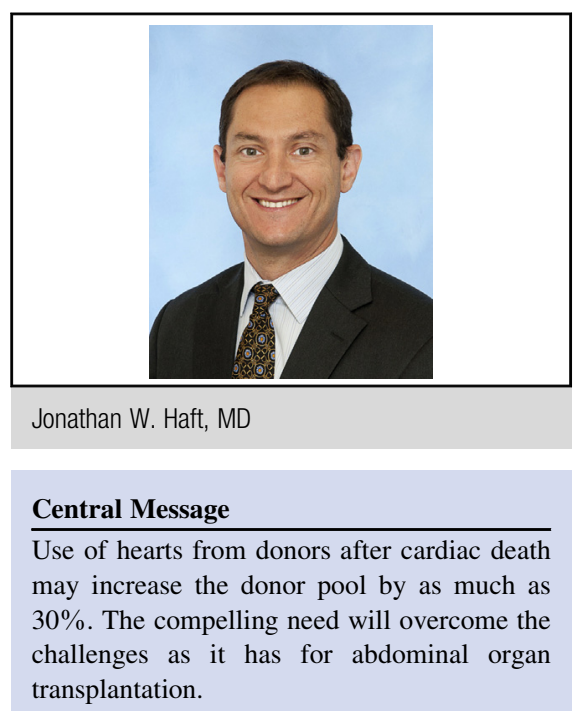

See Article page 512.

centers must be willing to accept a donor heart that has suffered prolonged warm ischemia leading to cardiac standstill without any means of characterizing postreanimation performance until after implantation. Finally, the donation and procurement logistics of DCD are complex, requiring substantially more time and carry a higher likelihood of organ discard from prolonged warm ischemia. Incorporation of these logistics into routine practice of a typical US transplant program will be cumbersome.

DCD has become an accepted source of donor kidneys, livers, and lungs, and its use is on the rise. Results from the United Kingdom and Australia clearly demonstrate the feasibility of DCD for cardiac transplantation. Ideally, a North American clinical trial should be initiated in which the benefits of a strategy of DCD heart use is analyzed in terms of posttransplant survival as well as impact on waitlist mortality and duration. A trial of this design would be costly and complex. Difficulties aside, Jawitz and Milano ${ }^{1}$ are correct in suggesting that the potential benefits are worth the investment.

\section{Reference}

1. Jawitz OK, Milano CA. Is it time for the United States to engage in heart transplantation using donation after circulatory death? J Thorac Cardiovasc Surg. 2020;159:512-3. 